\title{
Evaluation of reference genes for RT-qPCR study in abalone Haliotis discus hannai during heavy metal overload stress
}

\author{
Sang Yoon Lee ${ }^{1}$ and Yoon Kwon Nam ${ }^{1,2^{*}}$
}

\begin{abstract}
Background: The evaluation of suitable reference genes as normalization controls is a prerequisite requirement for launching quantitative reverse transcription-PCR (RT-qPCR)-based expression study. In order to select the stable reference genes in abalone Haliotis discus hannai tissues (gill and hepatopancreas) under heavy metal exposure conditions ( $\mathrm{Cu}, \mathrm{Zn}$, and $\mathrm{Cd}$ ), 12 potential candidate housekeeping genes were subjected to expression stability based on the comprehensive ranking while integrating four different statistical algorithms (geNorm, NormFinder, BestKeeper, and $\Delta C T$ method).

Results: Expression stability in the gill subset was determined as RPL7 $>R P L 8>A C T B>R P L 3>P P I B>R P L 7 A>E F 1 A>$ $R P L 4>G A P D H>R P L 5>U B E 2>B-T U$. On the other hand, the ranking in the subset for hepatopancreas was RPL7> $R P L 3>R P L 8>A C T B>R P L 4>E F 1 A>R P L 5>R P L 7 A>B-T U>U B E 2>P P I B>G A P D H$. The pairwise variation assessed by the geNorm program indicates that two reference genes could be sufficient for accurate normalization in both gill and hepatopancreas subsets. Overall, both gill and hepatopancreas subsets recommended ribosomal protein genes (particularly RPL7) as stable references, whereas traditional housekeepers such as $\beta$-tubulin (B-TU) and glyceraldehyde-3-phosphate dehydrogenase (GAPDH) genes were ranked as unstable genes. The validation of reference gene selection was confirmed with the quantitative assay of $M T$ transcripts.

Conclusions: The present analysis showed the importance of validating reference genes with multiple algorithmic approaches to select genes that are truly stable. Our results indicate that expression stability of a given reference gene could not always have consensus across tissue types. The data from this study could be a good guide for the future design of RT-qPCR studies with respect to metal regulation/detoxification and other related physiologies in this abalone species.
\end{abstract}

Keywords: Reference gene, RT-qPCR, Gene expression study, Abalone Haliotis discus hannai, Heavy metal overload

\section{Background}

Quantitative reverse transcription-PCR (RT-qPCR) has long been an established tool for the variety of gene expression assays owing to its cost effectiveness, sensitivity, reproducibility, and simplicity. This methodology has been commonly considered as the most reliable technique particularly for the quantitative validation of differentially expressed genes during a designed experimental treatment (Radonić et al. 2004; Udvardi et al.

\footnotetext{
* Correspondence: yoonknam@pknu.ac.kr

${ }^{1}$ Department of Marine Bio-Materials \& Aquaculture, Pukyong National University, Busan 48513, South Korea

${ }^{2}$ Center of Marine-Integrated Biomedical Technology (BK21 Plus Team), Pukyong National University, Busan 48513, South Korea
}

2008). Several factors affecting RT-qPCR results include variables associated with qualitative and quantitative differences of input RNA templates as well as efficiency and specificity of reactions. For this reason, in most cases, the amplifications of internal controls (normalization controls) in parallel with the gene(s) of interest have been unavoidable to overcome the noise generated by the variables above (Kubista et al. 2006; Bustin et al. 2009).

Classically known housekeeping genes (HKGs) such as cytoskeletal $\beta$-actin $(A C T B)$, glyceraldehyde-3-phosphate dehydrogenase (GAPDH), and 18S rRNA genes have been commonly used as internal standard in RT-qPCR based on the belief that these HKGs do not change their expression levels irrespective of experimental stimulatory 
treatments. However, a considerable number of recent studies have also claimed that these HKGs may not always be stable depending on aquatic species; they could be modulated by certain stimulatory treatments with variable expression levels under different physiological conditions (Li \& Shen 2013; Taylor et al. 2013; Yuan et al. 2014). Hence, careful validation of internal controls is now highly necessary prior to expression studies for target genes of interest. Different statistical software tools have become available with this purpose, and the potential utility of computational algorithms to select the best candidate reference gene has been broadly agreed upon in various gene expression studies (Vandesompele et al. 2002; Pfaffl et al. 2004; Silver et al. 2006).

Pacific abalone Haliotis discus hannai is one of the most commercially important mollusk species in Korean aquaculture domain. Because many abalone farms in Korea have used the sea-cage system in the coastal areas, waterborne toxicants existing in these areas have become serious concerns, affecting various physiologies of growing abalones (Wan et al. 2011; Park \& Kim 2013). In particular, heavy metals are one of the critical pollutants in coastal areas, caused by various anthropogenic and/or industrial activities. Due to their high bioaccumulation capability, negative effects of heavy metals are often thought to be widespread at multilevels of the aquatic food chains (Türkmen et al. 2008; Silva-Aciares et al. 2011; Song et al. 2014). Aquatic invertebrates especially including the benthic mollusks having basically sedentary characteristics have been recognized as a useful platform not only to study the effects of metal toxicants on the physiology of marine animals but also to develop an effective early-warning bioindicator of metal pollution in the coastal environments. Heavy metals are also known as potent pro-oxidant effectors, consequently leading the potential deregulation of various cellular events in the exposed organisms (Amiard et al. 2006; Kim et al. 2007). Hence, comprehensive understanding on the relevant gene expression patterns in response to metal exposures would be a fundamental basis to gain a better insight into the protective mechanism of the exposed animals against metal toxicants (Kim et al. 2007; Wang \& Rainbow 2005). Undoubtedly, the selection of suitable reference genes should be a prerequisite requirement for launching an expression analysis project regarding heavy metal exposures. However, despite its importance, the evaluation of stable reference genes from this abalone species in relation with heavy metal exposures has been little studied. Based on this need, the objective of this study was to validate different HKGs associated with heavy metal exposures as the initial step in environmental toxicogenomics of this abalone species.

\section{Methods}

\section{Abalone specimens}

Abalone specimens used in the present study were the stock that had been maintained in the Experimental Fish Culture Station of Pukyong National University (PKNU). During the pre-acclimation period (2 weeks), abalones have been maintained in rectangular $(1 \times 3 \times 0.5 \mathrm{~m}=$ $W \times L \times D)$ tanks equipped with protein skimmers Water temperature and dissolved oxygen throughout this period were adjusted to be $20 \pm 1^{\circ} \mathrm{C}$ and $8 \pm 1 \mathrm{ppm}$, respectively. Abalones were fed with commercial diet for abalones three times a day on an ad libitum basis, and daily water exchange rate was $50 \%$ using 1 - $\mu \mathrm{m}$-filtered seawater.

Experimental heavy metal exposures and tissue sampling Three sets of heavy metal exposure treatments were performed. First, juvenile abalones (average body weight $=$ $42.5 \pm 3.4 \mathrm{~g}$ and shell length $=7.2 \pm 0.5 \mathrm{~cm}$ ) were exposed to cadmium $(\mathrm{Cd})$, copper $(\mathrm{Cu})$, or zinc $(\mathrm{Zn})$. Heavy metal chemicals (analytical grade) were used (Sigma-Aldrich, St. Louis, MO, USA). Six individuals were assigned to one of three 50-L tanks containing $40 \mathrm{~L}$ seawater supplemented with each heavy metal. The dose strength of each heavy metal $(\mathrm{Cd}, \mathrm{Cu}$, or $\mathrm{Zn})$ was $0.5 \mathrm{ppm}$ as a nominal concentration. The non-exposed control group was also made identically except for the heavy metal. Two replicate tanks were prepared for each treatment group including the non-exposed control. Temperature (in-tank temperature) was adjusted to be ranged at $20 \pm 1{ }^{\circ} \mathrm{C}$ with room air conditioner, and dissolved oxygen was maintained to be $8 \pm$ $1 \mathrm{ppm}$ with an air-diffuser-connected aerator. Exposure duration was $24 \mathrm{~h}$. After $24 \mathrm{~h}$, three individuals were randomly chosen from each replicate tank (i.e., six individuals per treatment) and tissues (gill and hepatopancreas) were surgically removed from each individual abalone. Tissues were immediately frozen on dry ice and stored at $-80{ }^{\circ} \mathrm{C}$ until used for gene expression assay. Second, abalones (same sized as above) were exposed to different dose strengths $(0,0.1,0.25$, and $0.5 \mathrm{ppm})$ of $\mathrm{Cu}$ for $48 \mathrm{~h}$. The preparation of two replicate tanks each containing six individuals and other tank conditions were the same with those used for the first exposure experiment. Three individuals were sampled from each replicate tank $(n=6$ per treatment) in order to obtain the two tissue types (gill and hepatopancreas) from each individual. Third, abalones were exposed to $\mathrm{Cd}(0$ or $0.25 \mathrm{ppm})$ for different durations of 24, 48, and $72 \mathrm{~h}$. Twelve abalones were assigned into either one of four tanks (two replicate tanks for 0 and $0.25 \mathrm{ppm}$ ). Again, all other tank conditions were identically prepared with those mentioned above. During exposure treatments, no feed was provided, and the metal was renewed every $24 \mathrm{~h}$ with a daily water exchange rate of $20 \%$. At each time point, three individuals were randomly 
chosen from each replicate tank (six for Cd-exposed and six for non-exposed groups). Tissue sampling was carried out as described above. During the three exposure experiments, no mortality was observed.

\section{Selection of candidate internal control genes and primer design}

Based on searches against both a local transcriptome next-generation sequencing (NGS) database constructed with abalone tissues (unpublished data) and the public NCBI GenBank database (http://www.ncbi.nlm.nih.gov), 12 candidate HKGs were selected. They included cytoskeletal $\beta$-actin $(A C T B), \beta$-tubulin $(B-T U)$, elongation factor-1 alpha $(E F 1 A)$, glyceraldehyde-3-phosphate dehydrogenase $(G A P D H)$, peptidyl-prolyl cis-trans isomerase B (PPIB), ubiquitin-conjugating enzyme E2 (UBE2), and six kinds of ribosomal proteins (RPL3, RPL4, RPL5, RPL7, RPL7A, and RPL8). Partial nucleotide sequences of the genes selected from the NGS database were confirmed by RT-PCR cloning followed by direct sequencing. Correct annotation for each gene from the NGS database was confirmed by BLAST homology search against NCBI GenBank. For each gene, multiple primer pairs were designed considering primer length (20-22 bp), G+C contents (40-60 \%), melting temperature $\left(55-65{ }^{\circ} \mathrm{C}\right)$, and amplicon size (100$200 \mathrm{bp})$. The PCR efficiency $(E)$ for each gene was estimated using the known formula $\left[E=10^{(-1 / k)}-1\right.$, with $k=$ slop] (Kubista et al. 2006), based on the standard curve prepared with 4-log serial dilution points of abalone complementary DNA (cDNA) samples. LightCycler 480 Real-Time PCR System (Roche Life Science, Mannheim, Germany) was used for all the qPCR experiments in this study. Based on a series of preliminary evaluations, the optimal pair of primers was selected for each gene for further use in expression stability analysis. The summarized information on the genes and oligonucleotide primers used in the present study is provided in Table 1 . The amplification of a single specific product using the best primer pair optimized for each gene was confirmed with end-point RT-PCR (Fig. 1).

Table 1 Summary on housekeeping reference genes and qPCR assay conditions used in this study

\begin{tabular}{|c|c|c|c|c|c|c|}
\hline Gene & Description & Accession no. & Primer sequence $\left(5^{\prime}-3^{\prime}\right)$ & Amplicon size (bp) & $\mathrm{PCR}(E)^{\mathrm{a}}$ & $R^{2}$ value \\
\hline \multirow[t]{2}{*}{ ACTB } & Cytoskeletal $\beta$-actin & AY380809.1 & FW: GGTATTGTTCTGGACTCTGG & 162 & 1.968 & 0.996 \\
\hline & & & RV: GGTGGTGGTGAATGAGTAAC & & & \\
\hline \multirow[t]{2}{*}{$B-T U$} & $\beta$-tubulin & EF103431.1 & FW: ACATTCACTAGGTGGGGGTA & 161 & 1.976 & 0.998 \\
\hline & & & RV: GTACTGACAATGTGGCGTTG & & & \\
\hline \multirow[t]{2}{*}{ EF1A } & Elongation factor-1 alpha & JX002677.1 & FW: GCTCTCTGGAAGTITGAGAC & 165 & 1.974 & 0.994 \\
\hline & & & RV: CTCCTTCGAGATACCAGCTT & & & \\
\hline \multirow[t]{2}{*}{ GAPDH } & Glyceraldehyde-3-phosphate dehydrogenase & ABO26632.1 & FW: ACCGCTACACAGAAGACAGT & 177 & 1.912 & 0.995 \\
\hline & & & RV: TACATCAGGTACTGGGACAC & & & \\
\hline \multirow[t]{2}{*}{ PPIB } & Peptidyl-prolyl cis-trans isomerase B & KP698942 & FW: CGAGAAAGCAGGACGAATTG & 171 & 1.977 & 0.993 \\
\hline & & & RV: AAGTCCCCTCCTTGGATCAT & & & \\
\hline \multirow[t]{2}{*}{ RPL3 } & Ribosomal protein L3 & KP698943 & FW: TCATTGCACACACCCAGACT & 168 & 1.911 & 0.997 \\
\hline & & & RV: CAATGACCTCATCCTGTTCG & & & \\
\hline \multirow[t]{2}{*}{ RPL4 } & Ribosomal protein $L 4$ & KP698944 & FW: GCTGCTTCAAGACCGCTTAT & 176 & 2.013 & 0.992 \\
\hline & & & RV: TGGCCAGCTITCTCTGAAAC & & & \\
\hline \multirow[t]{2}{*}{ RPL5 } & Ribosomal protein $L 5$ & ABO26701.1 & FW: AGATGAGGATGGCAAACCAG & 168 & 1.937 & 0.996 \\
\hline & & & RV: TCGCTGCTCTCAGAGTCAAA & & & \\
\hline \multirow[t]{2}{*}{ RPL7 } & Ribosomal protein $L 7$ & KP698945 & FW: CAAGCTGAACACTCCAAACG & 156 & 1.997 & 0.994 \\
\hline & & & RV: TCCACAGCACTGATGTITCC & & & \\
\hline \multirow[t]{2}{*}{ RPL7A } & Ribosomal protein L7A & KP698946 & FW: GCTGTCGAAAAAGGTTGAGC & 165 & 1.972 & 0.995 \\
\hline & & & RV: TGCTTCAAGACAGCGAACTG & & & \\
\hline \multirow[t]{2}{*}{ RPL8 } & Ribosomal protein L8 & KP698947 & FW: TGGAAACTACGCCACAGTCA & 161 & 1.944 & 0.995 \\
\hline & & & RV: GTCCTGCCTTCAACATTGGT & & & \\
\hline \multirow[t]{2}{*}{ UBE2 } & Ubiquitin-conjugating enzyme E2 & KP698948 & FW: CCAAGCTCTTCTTAGTGCAC & 170 & 1.954 & 0.997 \\
\hline & & & RV: CTCCCCACTTCCATCACTTT & & & \\
\hline
\end{tabular}




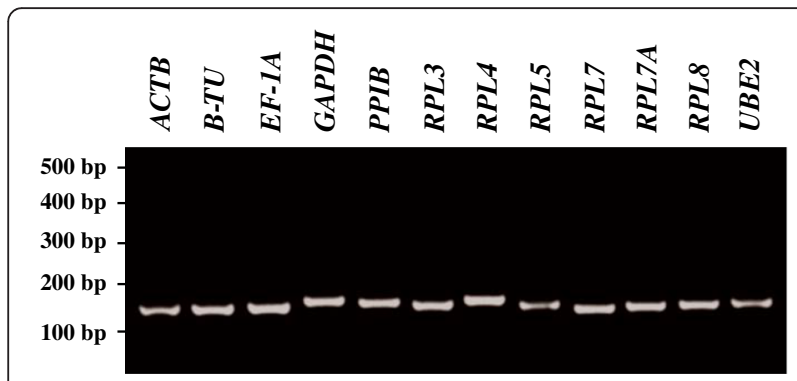

Fig. 1 Representative end-point gel showing the specific amplification of the single PCR band for each of 12 candidate reference genes tested in this study. PCR products were run on $2 \%$ agarose gel and visualized by ethidium-bromide staining. The description for each gene symbol can be referred to in Table 1

\section{RNA purification, CDNA synthesis, and RT-qPCR}

Total RNA from either gill or hepatopancreas was extracted using TriPure Reagent (Roche Applied Science) and further purified by using RNeasy Plus Mini Kit (Qiagen, Hilden, Germany) and RNase-Free DNase Set Kit (Qiagen) according to the manufacturers' instructions. The quality and quantity of purified total RNA was checked with Libar S70 spectrophotometer (Biochrom Ltd., Cambridge, UK) at 230, 260, and $280 \mathrm{~nm}$, in which only the RNA samples showing the absorbance values greater than 1.8 for both $A_{260 / 280}$ and $A_{260 / 230}$ ratios were considered for use. The integrity of selected RNA sample was validated with $1 \%$ MOPS formaldehyde agarose gel electrophoresis. The absence of genomic DNA contamination in the purified RNA samples was confirmed by no amplification product (the intronic fragment of abalone actin gene) in the PCR reaction without RT reaction (data not shown). An aliquot $(2 \mu \mathrm{g})$ of total RNA from each sample was reverse transcribed into cDNA using Omniscript RT Kit (Qiagen) according to the manufacturer's recommendation. The RT product (cDNA) was diluted fourfold with DNase-free distilled water and $2 \mu \mathrm{L}$ was subjected to PCR amplification. Thermal cycling in a reaction volume of $20 \mu \mathrm{L}$ was performed with Light Cycler 480 System (Roche Applied Science) and SYBR Green I Master (Roche Applied Science) under the following conditions: initial denaturation step (at $95{ }^{\circ} \mathrm{C}$ for $10 \mathrm{~min}$ ) followed by 40 cycles of $20 \mathrm{~s}$ at $95{ }^{\circ} \mathrm{C}, 20 \mathrm{~s}$ at $58{ }^{\circ} \mathrm{C}$, and $20 \mathrm{~s}$ at $72{ }^{\circ} \mathrm{C}$ with an initial denaturation step at $94{ }^{\circ} \mathrm{C}$ for $2 \mathrm{~min}$. For each sample, triplicate reactions were performed. The specificity of the amplification product was verified by melting curve analysis with the default setting in the thermal cycler. All the samples were assayed three times for technical replications.

\section{Data subsets and expression stability analysis}

Raw quantification cycle $(\mathrm{Cq})$ data obtained were divided into two main datasets on the basis of tissue types because the transcriptional responses of certain target gene(s) to metal-stimulated treatment should be usually interpreted in a tissue-specific fashion. In the present study, we selected gill and hepatopancreas tissues, the two main organs with respect to the uptake and bioprocess of heavy metal ions in aquatic organisms. In order to evaluate the expression stability of candidate reference genes in either tissue type, the first dataset comprised of gill samples $(n=84$ including biological replications), while the second dataset consisted of 84 hepatopancreas samples from non-exposed and metalexposed groups. For each biological sample (i.e., individual cDNA sample) from either tissue types, technical replications of the $\mathrm{qPCR}$ assay were made in triplicates to determine the median value of each biological sample, and afterward, the control cycle threshold $(\mathrm{Ct})$ values (i.e., biological replications) within an exposure treatment set were averaged in order to prevent the proportion of data from non-exposed control groups from being too high in the raw datasets.

To evaluate the expression stability of the HKGs tested, the RT-qPCR data was statistically analyzed using different types of software programs, geNorm (qBasePLUS ver. 3.0) (Vandesompele et al. 2002; Hellemans et al. 2007), NormFinder (ver. 0.953) (Andersen et al. 2004), BestKeeper (Pfaffl et al. 2004), and comparative delta $\mathrm{Ct}(\triangle \mathrm{CT})$ method (Silver et al. 2006). For geNorm, the lower $\mathrm{Cq}$ value (i.e., the maximum expression level) from each gene was used as a calibrator and was arbitrarily set $=1$. The geNorm algorithm calculates an expression stability value $(M)$ for each gene and then compares the pairwise variation $(V)$ of this gene with the others. The cutoff levels for $M$ and $V$ values were set to 1.5 and 0.15 , respectively. Candidate genes with the lowest $M$ value were considered to be the most stable under tested experimental conditions. The minimum number of reference genes for accurate normalization was also estimated by the $V$ value in the geNorm program. For NormFinder, the same input file format as the geNorm was adopted; however, $\mathrm{Cq}$ values were converted into relative quantities after correcting the PCR efficiencies. For BestKeeper, untransformed Ct values and PCR efficiency $(E)$ were used to determine the best suited standards and to combine them into an index by the coefficient of determination and the $P$ value based on the geometric mean of the $\mathrm{Cq}$ values. The $\Delta \mathrm{CT}$ method compares the relative expression of pairs of genes within each sample to confidently identify useful HKGs. Finally, comprehensive ranking to identify the most appropriate control gene was determined using the software RefFinder (http://fulxie.Ofees.us/?type=reference\&ckattempt=1), in which the four abovementioned software programs were integrated to compare the ranking of the tested candidate reference genes. Based on the rankings from 
each program, RefFinder assigns an appropriate weight to an individual gene and calculates the geometric mean of their weights for the overall final ranking.

\section{Validation of reference gene selection}

Based on comprehensive rankings of the candidate reference genes, the suitability of selected reference genes was validated with the gene expression assay of metallothionein $(M T)$ in response to heavy metal exposure treatment. The gill and hepatopancreas cDNA samples both from the Cd-exposed (treated at $0.25 \mathrm{ppm} \mathrm{Cd}$ for $24 \mathrm{~h}$ ) and non-exposed control groups were subjected to qPCR quantification of $M T$ transcripts with different normalization genes. A segment of MT cDNA (GenBank accession no. KT895222) was amplified by qPCR using a pair of primers (MT-FW: 5'-GGTACCGACTGCAA GTGTAA-3' and MT-RV: 5' -TCATCGGAAGTCATGT GAGC-3'; amplicon size $=189$ bp; $E=1.94$ ) under the amplification conditions as described above for reference genes. The expression level of $M T$ transcripts was normalized against the most stable reference gene (ranked to the top; R1), the two most stable reference genes $(\mathrm{R} 1+\mathrm{R} 2)$, the second unstable reference gene (R11), or the least stable gene (ranked to the bottom; R12). Expression levels of $M T$ transcripts in the gill and hepatopancreas tissues from the $\mathrm{Cd}$-exposed abalones were presented as the fold difference to those from non-exposed control group using the formula $2^{-\Delta \Delta C t}$ (Schmittgen \& Livak 2008) based on the normalization of $M T$ transcript levels against the expression levels of its own reference genes $(R 1, R 1+R 2, R 11$, and $R 12)$. The effect of the reference gene selection was examined if differential levels of $M T$ transcripts could be presented depending on the reference genes selected. Calculated levels of $M T$ transcripts in gill and hepatopancreas based on each normalization regime were subjected to one-way ANOVA followed by Duncan's multiple range tests in order to examine statistical significance at $P=0.05$.

\section{Results}

\section{Expression profiles of the candidate reference genes}

From technical and biological replicates, the efficiency of RT-qPCR calculated for each candidate reference gene was proven to range from 1.911 (RPL3) to 2.013 (RPL4) (Table 1). Also, every primer pair used in the present qPCR assays successfully revealed a single peak from the melting curve analysis (data not shown), indicating that the specific amplification for each candidate gene segment could be achieved. Of the 12 candidate reference genes tested, $B-T U$ was the least expressed (the highest mean Cq values) gene in the gill subsets, whereas RPL7 was the most expressed gene in this tissue type. Considering the variation among samples in a given gill tissue,
$B-T U, E F 1 A, G A P D H, R P L 3, R P L 5$, and $U B E 2$ exhibited relatively greater variation in their expression levels than other candidate genes. In the subset of the hepatopancreas also, B-TU and RPL7 showed the least and highest expression levels, respectively, as similarly in the gill, although their absolute mean $\mathrm{Cq}$ values were different from those observed in the subset of the gill (Fig. 2).

\section{Expression stability in the subset of abalone gills}

Based on the evaluation with four different statistical approaches (geNorm, NormFinder, BestKeeper, and $\triangle \mathrm{CT}$ method) followed by ranking decision with the RefFinder tool, all the four approaches did not recommend the same reference gene for the most suitable internal control gene (Table 2). According to the geNorm algorithm, the RPL8 was the most stable candidate gene in the gill, followed by RPL7 and $A C T B$. On the other hand, geNorm pointed $B-T U$ and $U B E 2$ as the two most unstable HKGs in the gill related with heavy metal exposures. NormFinder also recommended RPL7, followed by $R P L 8$, for the most stable references while indicated $B$ $T U$ as the most variable gene. According to BestKeeper, RPL7 and RPL8 turned out to be the most stable in the gill, whereas $B-T U$ and $U B E 2$ were pointed as the least stable candidates, although all the 12 genes tested showed SD values lower than 1 . For the most stable candidate genes, according to the $\triangle \mathrm{CT}$ method, the RPL7 gene was the first gene of the rank in the gill, while $B$ $T U$ was the last gene. Collectively, based on the geometric mean-based ranking with RefFinder integrating the four statistical approaches, comprehensive ranking of each candidate gene was provided according to their stability, in which genes with lower ranking were considered to be most stably or invariantly expressed in the gill under heavy metal exposure conditions. As shown in Table 2, the recommended comprehensive ranking of the stability in the gill was determined as RPL7>RPL8 > $A C T B>R P L 3>$ PPIB $>$ RPL7A $>$ EF1A $>$ RPL4 $>$ GAPDH $>$ $R P L 5>U B E 2>B-T U$. Overall, the results indicate RPL7 could be considered as the ideal reference gene in the gill regarding metal exposure experiment in this abalone species, while $U B E 2$ and $B-T U$ would be the worst or unstable references that are not recommended for the use in this case.

\section{Expression stability in the subset of abalone hepatopancreas}

The stability ranking of candidate reference genes in the subset for the hepatopancreas was not exactly the same with that ordered in the gill, although the most stable reference gene finally recommended by the RefFinder program was the RPL7 in both tissue types (Table 3). With the geNorm program, the most stable candidates were RPL8 and $A C T B$ while $B-T U$ and GAPDH were the 

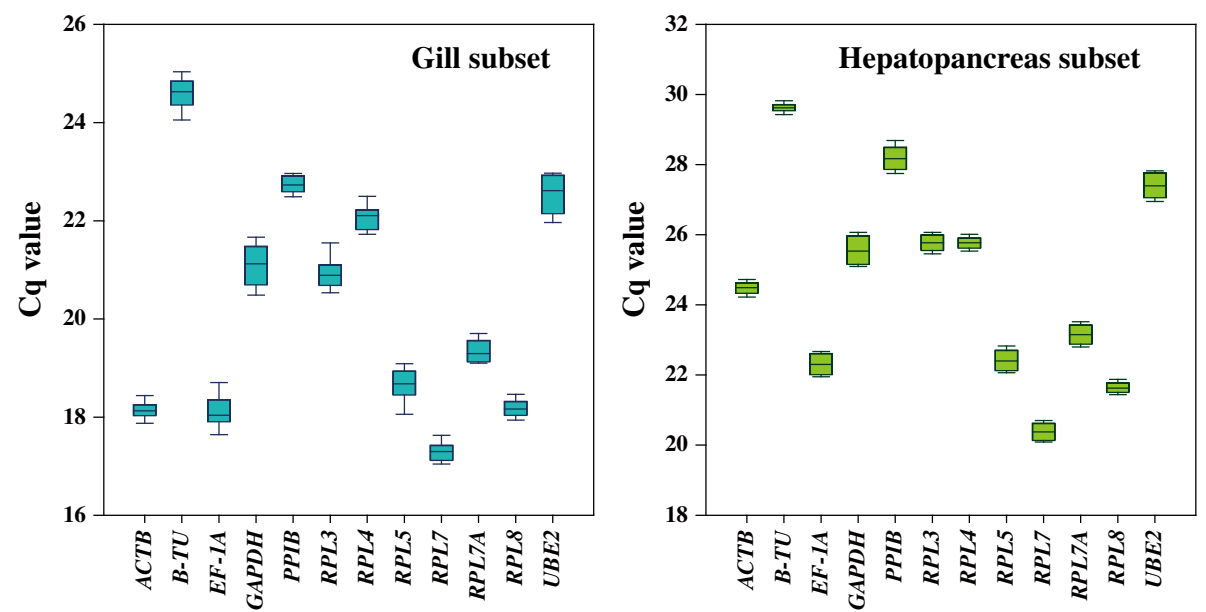

Fig. 2 Expression profiles (Cq values) of the 12 candidate reference genes in the abalone gill and hepatopancreas subsets. In the box plot, the lower and upper boundaries of each box indicate the 25th and 75th percentiles, respectively. A line within the box marks the median value. Whiskers above and below the box indicate the 90th and 10th percentiles, respectively

most variable references. NormFinder also pointed $G A P D H$ as one of the least stable candidates whereas $R P L 7$ and RPL3 were recommended as very stable references. On the other hand, BestKeeper showed slightly different patterns of rankings in the sense that B-TU, which was recognized as one of the least stable genes in other algorithms, was recommended as the most stable gene. This highest stability was followed by RPL8. However, for the least stable candidate reference genes, the GAPDH was called again by the BestKeeper approach. According to the $\triangle C T$ method, the most stable candidate was RPL7 while the most unstable gene was $B$ $T U$. Taken together, the comprehensive ranking determined by RefFinder for the subset in hepatopancreas was $R P L 7>R P L 3>R P L 8>A C T B>R P L 4>E F 1 A>R P L 5>$ $R P L 7 A>B-T U>U B E 2>P P I B>G A P D H$.

\section{Pairwise variation analysis using geNorm}

With the geNorm software program, the minimum number of reference genes for accurate normalization was determined based on the calculation of the pairwise variation $V_{n} / V_{n+1}$ between two sequential normalization factors to consider the necessity of adding the next reference gene, in which large variation means that the newly added gene should have a significant effect on the normalization accuracy and hence be added for calculation. Considering the recommended cutoff value of 0.15 , the $V_{2} / V_{3}$ value (0.066) observed in the gill criterion was

Table 2 Expression stability ranking of 12 candidate reference genes during heavy metal exposures in the gill of different treatment sets

\begin{tabular}{|c|c|c|c|c|c|c|c|c|c|}
\hline \multicolumn{2}{|l|}{ RefFinder } & \multicolumn{2}{|l|}{ geNorm } & \multicolumn{2}{|c|}{ NormFinder } & \multicolumn{2}{|c|}{ BestKeeper } & \multicolumn{2}{|c|}{ Delta CT } \\
\hline Genes & GRV & Genes & SV (M) & Genes & SV & Genes & $\mathrm{SD}[ \pm \mathrm{CP}]$ & Genes & Ave. SD \\
\hline RPL7 & 1.000 & RPL8 & 0.199 & RPL7 & 0.146 & RPL7 & 0.117 & RPL7 & 0.317 \\
\hline RPL8 & 1.682 & RPL7 & 0.204 & RPL8 & 0.150 & RPL8 & 0.137 & RPL8 & 0.320 \\
\hline ACTB & 3.834 & ACTB & 0.209 & RPL3 & 0.211 & ACTB & 0.169 & RPL3 & 0.352 \\
\hline$R P L 3$ & 4.559 & $R P L 7 A$ & 0.236 & ACTB & 0.215 & $P P I B$ & 0.188 & PPIB & 0.353 \\
\hline PPIB & 4.681 & PPIB & 0.250 & $R P L 7 A$ & 0.218 & $R P L 7 A$ & 0.192 & $R P L 7 A$ & 0.353 \\
\hline$R P L 7 A$ & 4.729 & RPL3 & 0.266 & PPIB & 0.219 & EF1A & 0.199 & ACTB & 0.355 \\
\hline EF1A & 6.735 & EF1A & 0.280 & EF1A & 0.227 & RPL4 & 0.203 & EF1A & 0.360 \\
\hline RPL4 & 7.7737 & RPL4 & 0.290 & RPL4 & 0.231 & RPL3 & 0.207 & RPL4 & 0.364 \\
\hline GAPDH & 9.000 & GAPDH & 0.304 & GAPDH & 0.282 & GAPDH & 0.280 & GAPDH & 0.397 \\
\hline RPL5 & 10.488 & RPL5 & 0.329 & UBE2 & 0.376 & RPL5 & 0.316 & UBE2 & 0.465 \\
\hline UBE2 & 10.719 & UBE2 & 0.352 & RPL5 & 0.408 & $B-T U$ & 0.321 & RPL5 & 0.479 \\
\hline$B-T U$ & 11.742 & $B-T U$ & 0.392 & $B-T U$ & 0.539 & UBE2 & 0.341 & $B-T U$ & 0.593 \\
\hline
\end{tabular}


Table 3 Expression stability ranking of 12 candidate reference genes during heavy metal exposures in the hepatopancreas of different treatment sets

\begin{tabular}{|c|c|c|c|c|c|c|c|c|c|}
\hline \multicolumn{2}{|c|}{ RefFinder } & \multicolumn{2}{|l|}{ geNorm } & \multicolumn{2}{|c|}{ NormFinder } & \multicolumn{2}{|c|}{ BestKeeper } & \multicolumn{2}{|c|}{ Delta CT } \\
\hline Genes & GRV & Genes & SV (M) & Genes & SV & Genes & $\mathrm{SD}[ \pm \mathrm{CP}]$ & Genes & Ave. SD \\
\hline$\overline{R P L 7}$ & 2.340 & RPL8 & 0.059 & RPL7 & 0.023 & $B-T U$ & 0.100 & RPL7 & 0.103 \\
\hline RPL3 & 2.991 & ACTB & 0.060 & $R P L 3$ & 0.047 & RPL8 & 0.127 & RPL3 & 0.113 \\
\hline RPL8 & 3.364 & RPL4 & 0.061 & EFIA & 0.055 & RPL4 & 0.129 & $E F 1 A$ & 0.115 \\
\hline ACTB & 3.600 & RPL3 & 0.074 & RPL5 & 0.058 & ACTB & 0.133 & RPL5 & 0.117 \\
\hline RPL4 & 4.409 & RPL7 & 0.079 & $R P L 7 A$ & 0.069 & RPL3 & 0.174 & $R P L 7 A$ & 0.126 \\
\hline EF1A & 4.695 & EFIA & 0.090 & RPL4 & 0.101 & RPL7 & 0.191 & $A C T B$ & 0.135 \\
\hline RPL5 & 5.471 & RPL5 & 0.096 & $A C T B$ & 0.101 & $R P L 7 A$ & 0.202 & RPL4 & 0.136 \\
\hline$R P L 7 A$ & 6.117 & $R P L 7 A$ & 0.101 & RPL8 & 0.105 & RPL5 & 0.225 & RPL8 & 0.139 \\
\hline$B-T U$ & 6.447 & UBE2 & 0.111 & UBE2 & 0.116 & EF1A & 0.229 & UBE2 & 0.146 \\
\hline UBE2 & 9.463 & $P P I B$ & 0.119 & PPIB & 0.136 & $P P I B$ & 0.257 & $P P I B$ & 0.161 \\
\hline$P P I B$ & 10.000 & GAPDH & 0.127 & GAPDH & 0.156 & UBE2 & 0.268 & GAPDH & 0.174 \\
\hline GAPDH & 11.242 & $B-T U$ & 0.139 & $B-T U$ & 0.185 & GAPDH & 0.308 & $B-T U$ & 0.199 \\
\hline
\end{tabular}

much lower than the proposed cutoff value, suggesting that two reference genes are sufficient enough for the precise normalization of gene expression data in the gill samples regarding heavy metal exposures. Pairwise variation in the hepatopancreas subset also indicated that two reference genes could be very sufficient for accurate normalization in relation with the metal exposures in the present study, as evidenced by the $V_{2} / V_{3}$ value of 0.020 (cutoff value $=0.15)$ (Fig. 3$)$.

\section{Validation of reference genes}

Stable or unstable reference genes showed different results in the interpretation of transcriptional responses of the $M T$ gene to the Cd exposure (Fig. 4). In the gill, the most stable reference $(\mathrm{R} 1 ; \mathrm{RPL7})$ and the combination of the two most stable references $(\mathrm{R} 1+\mathrm{R} 2 ; R P L 7+R P L 8$ based on the geNorm analysis) resulted in the similar amounts of $M T$ transcripts induced during exposure (about 4.4-fold relative to non-exposed control group) $(P>0.05)$. However, when normalized to R11 (GAPDH) or $\mathrm{R} 12(B-T U)$, the calculated amounts of the $M T$ transcripts in the gill of $\mathrm{Cd}$-exposed abalones were only less than threefold relative to non-exposed controls $(P<0.05)$. In the hepatopancreas also, differential levels of the $M T$ gene expression were visualized depending upon the reference genes selected. Similar with the finding from the gill tissue, the hepatic $M T$ expression levels normalized to either $\mathrm{R} 1$ (RPL7) or $\mathrm{R} 1+\mathrm{R} 2(R P L 7+R P L 3)$ were similar with each other (about twofold relative to non-exposed control) $(P>0.05)$. However, the normalization regime using $\mathrm{R} 11$ $(P P I B)$ or R12 (GAPDH) calculated the induced fold of $M T$ transcripts in hepatopancreas to be more than fourfold as compared to the basal expression observed in the non-exposed control group $(P<0.05)$.

\section{Discussion}

Recently, the necessity to evaluate the stability of reference genes themselves prior to RT-qPCR assay for target genes of interest has been claimed by a number of studies to report that traditional reference transcripts may

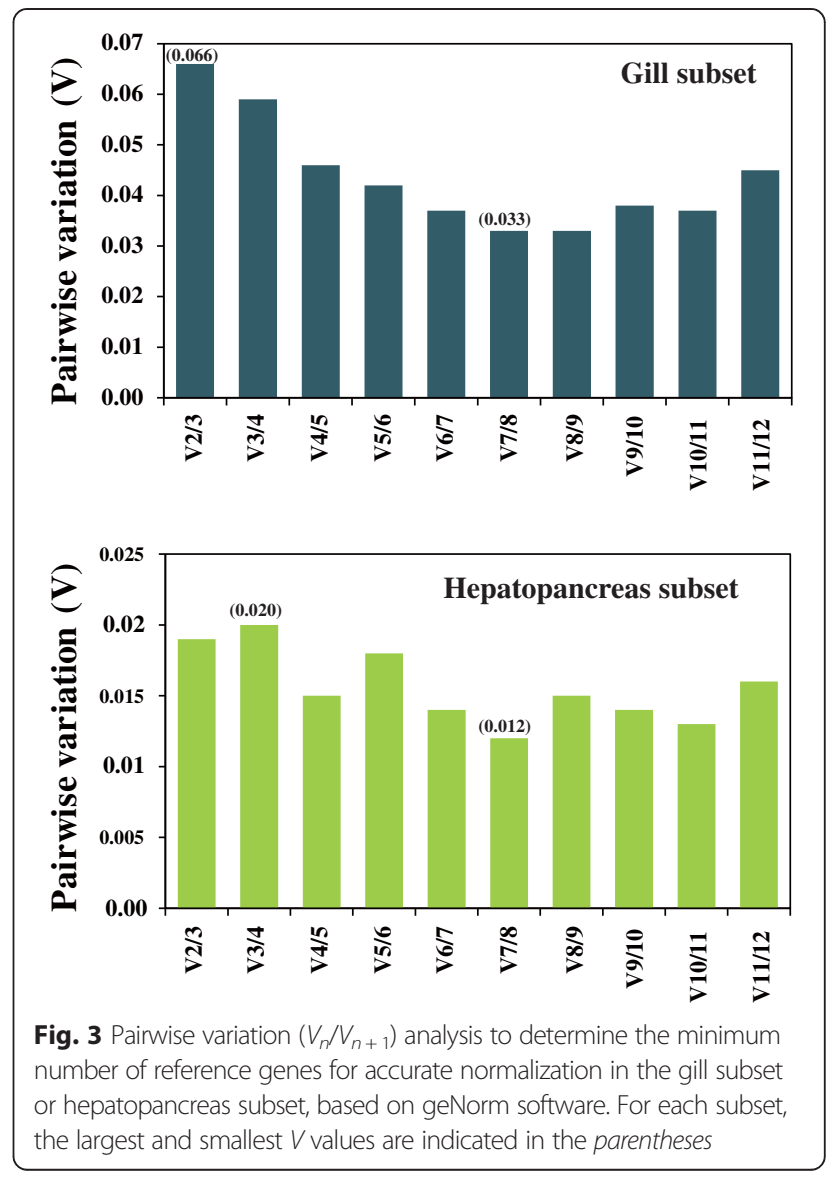



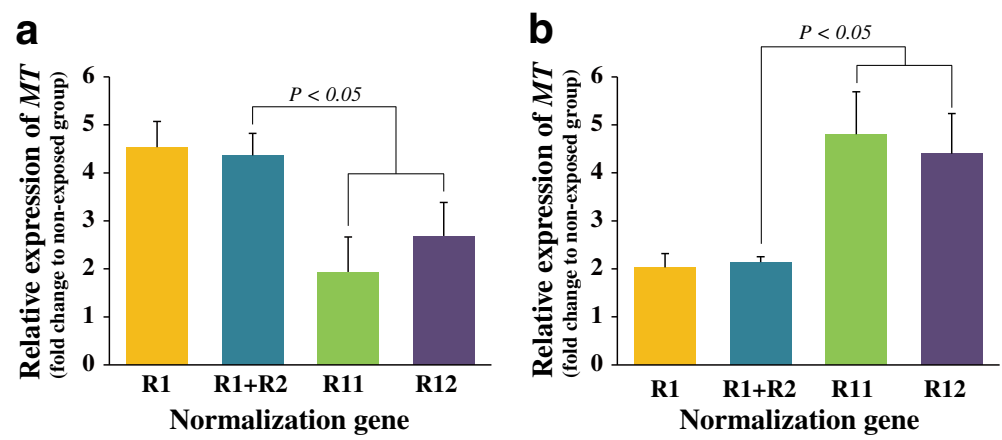

Fig. 4 Validation of reference gene selection with the quantitative RT-qPCR assay of metallothionein (MT) transcripts in the gill (a) and hepatopancreas (b) subsets. MT expression levels in the Cd-exposed group were normalized against the most stable reference gene (R1), the two most stable references $(R 1+R 2)$, the second least stable reference (R11), and the most unstable reference gene (R12). The statistical difference among the expression levels of $M T$ transcripts calculated with different normalization genes is indicated based on ANOVA at $P=0.05$

not always show constitutive expression as has often been assumed. It has already been widely agreed that no given single reference gene can be universally applied to all the experimental conditions and the utility of certain candidate reference genes could significantly vary among biotic and abiotic parameters including species, developmental stages, tissue types, and kinds of experimental treatments (Guénin et al. 2009; De Santis et al. 2011). For this reason, the case-specific choice of best reference gene for RT-qPCR may be unavoidable in many situations. In our case, we aimed to validate suitable reference genes from two subsets of tissue types (gill and hepatopancreas) in abalone regarding heavy metal exposures. Regarding gene expression studies of abalone tissues in response to heavy metal exposures, the gill is one of the most important biological barriers between internal and external environments of aquatic animals (Wang \& Rainbow 2005; Hwang et al. 2011), and the hepatopancreas is the main organ responsible for deposits and metabolic detoxification of trace metals in aquatic invertebrates (Rainbow 2007). In this study, we performed two sets of heavy metal exposures (i.e., exposure to different heavy metals, $\mathrm{Cu}, \mathrm{Zn}, \mathrm{Cd}$, and exposure to different doses of a given metal, $\mathrm{Cu}$ ), and the raw RTqPCR data were pooled into two subsets of tissue types (gill and hepatopancreas) in order to evaluate the expression stability of candidate reference genes in a tissue-specific fashion. The exposure conditions similar with those in the present study have already been proven to induce pro-oxidant stresses in abalone species belonging to Haliotidae (Kim et al. 2007).

For the reliable RT-qPCR, the high efficiency and specificity of PCR should be fulfilled. In our case, the calculated PCR efficiency $(E)$ value for each candidate gene tested was at least higher than $90 \%$. Recommended efficiency values vary between 90 and $110 \%$ (Schmittgen \& Livak 2008; Doak \& Zair 2012), and high $E$ has been reported to be usually correlated with robust and precise interpretation of the gene expression (Bustin et al. 2009). The presence of a single peak for melting curve analysis with each PCR reaction also suggests that the specific amplification is carried out in the present conditions. Consequently, our RT-qPCR assay conditions comply well with typically known recommendations.

In the present study, we choose a total of 12 candidate reference genes including traditionally used genes (i.e., $A C T B$ and GAPDH) but excluded the 18S rRNA, one of the most popular reference genes. The reason of exclusion was that $18 \mathrm{~S}$ rRNA is not a poly $(\mathrm{A}+)$-tailed RNA; therefore, the random priming for $\mathrm{RT}$ reaction is, at least in part, mandatory and the oligo- $\mathrm{d}(\mathrm{T})$ priming may not be applicable to this RNA type. In this case, due to its extremely high abundance, signal saturation obtained at very low $\mathrm{Ct}$ values might often be problematic unless template cDNA for the samples analyzed with $18 \mathrm{~S}$ primers were diluted at least a hundredfold relative to all other candidate genes. Further, such a dilution procedure may cause a risk to introduce a random element of variability (Le et al. 2012). Alternatively, the $18 \mathrm{~S}$ rRNA template could be prepared during an oligo- $\mathrm{d}(\mathrm{T})$-primed $\mathrm{RT}$ reaction by adding an $18 \mathrm{~S}$ rRNA-specific reverse primer at a very low final concentration (also called Co-RT method) (Zhu \& Altmann 2005). However, in this case also, potential variability related with differential reverse transcription efficiencies between poly $(\mathrm{A}+)$-tailed mRNA and abundant $18 \mathrm{~S}$ rRNA should be taken into account. Although 18S rRNA has still been one of the versatile calibrators in many gene expression studies, many other studies also have argued that 18S rRNA should be considered as one of the not-recommended references in organisms belonging to a wide array of taxonomic positions (Taylor et al. 2013; Yuan et al. 2014; Shen et al. 2010). Twelve candidates selected in the present study are assigned to several categories of functional ontology such as cytoskeletal cell shape and mobility (ACTB and $B-T U)$, energy metabolism $(G A P D H)$, translation and 
protein synthesis (EF1A and various RPLs), and protein metabolism and degradation (UBE2). Such a selection regime might also be of importance for adopting software programs and interpreting outputs, since the algorithms used by each program differ from one another. For example, the geNorm usually requires a gene number $\geq 7$ for a more reliable estimation and has the potential to detect co-regulated genes because its estimate is based on the pairwise comparison of the similarity of all the reference genes concerned (Vandesompele et al. 2002). On the other hand, the NormFinder calculates the variations within groups and between groups and it is less likely to detect co-regulation (Andersen et al. 2004). According to these, for more reliability, enough number of reference genes potentially belonging to different functional categories is recommended, and our selection regime is congruent with this requirement.

From expression stability tests, the two subsets of tissue types (gill and hepatopancreas) for abalones under either metal-exposed or non-exposed conditions shared a similar ranking pattern as judged by RefFinder in the sense that both subsets recommended equally the RPL7 as the most stable candidate gene while pointing the traditional candidate GAPDH as a very unstable (second most unstable and the first most unstable in the gill and hepatopancreas, respectively) reference gene. Our finding on the high stability of RPL7 reference genes is in accordance with previous reports with aquatic animals including oyster (Crassostrea gigas; Du et al. 2013), medaka (Oryzias latipes; Zhang \& Hu 2007), and halibut (Hippoglossus hippoglossus; Øvergård et al. 2010), although the RPL7 gene has been little recommended in abalone species so far. Meanwhile, the other ribosomal protein gene RPL5 has been recommended as the most stable gene in different-sized groups of red abalone (Haliotis rufescens; López-Landavery et al. 2014) and also disk abalone (Haliotis discus discus) broodstock exposed to xenobiotics (Wan et al. 2011). In the present study, RPL5 showed a clear tendency of tissue dependency in its stability during metal exposures where it was ranked as one of the least stable candidates in the gill; in contrast, it was the third most stable gene in the hepatopancreas. It suggests the importance of validating reference genes according to not only the experimental conditions but also tissue types under evaluation. $G A P D H$, the unstable gene with substantial variations in this study, encodes a known glycolytic enzyme responsible for carbohydrate metabolism. Due to its classical housekeeping role, GAPDH mRNA expression has been commonly recognized as an invariant internal standard. However, from the last decades, substantial claims have arisen to report that GAPDH is no longer a classical HKG that is involved solely with carbohydrate metabolism. Instead, GAPDH protein has been now recognized as a multiplayer associated with diverse cellular pathways especially including stress response, apoptosis, and innate immunity (Cho et al. 2008; Lee et al. 2013). Further, from aquatic animals, the upstream regulatory regions (i.e., 5 '-flanking regions) of the GAPDH gene have been reported to reveal binding motifs targeted by various transcription factors that have been known to be potentially involved in the stress response pathways and/or innate immunity, which is also congruent with the potential variability of GAPDH gene expression during experimental challenges or treatments (Lee et al. 2013). As previously known, heavy metals are a potent inducer for cellular oxidative stress often accompanied with inflammations and apoptotic changes in certain cell types; thus, metal exposure has the potential to modulate GAPDH genes in aquatic animals, as evidenced by the mud loach (Misgurnus mizolepis; Cypriniformes) (Cho et al. 2011).

On the other hand, $A C T B$ was recommended as the third and fourth most stable gene in the gill and hepatopancreas, respectively. $A C T B$ is one of the most common references used for gene expression experiments also in aquatic animals; however, the utility as an internal control has been reported to be largely controversial among studies. Notably, a recent study with different abalone species (red abalone $H$. rufescens) reported that $A C T B$ was the least stable reference in the hepatopancreas (López-Landavery et al. 2014). The unstable feature of the $A C T B$ gene was also reported in this abalone species during bacterial challenge (Qiu et al. 2013). The significantly different basal levels of the $A C T B$ transcripts across different tissues in aquatic animals might also be, at least in part, supportive of our finding with this abalone species (Cho et al. 2011; Kim et al. 2008). Meanwhile, other two commonly known HKGs, B-TU and $U B E 2$, did not receive high stability values in either the gill or hepatopancreas subset in this study, which is different from previous observations with other aquatic animals which report fairly good suitability of these HKGs as internal control standards under various experimental conditions (Fernandes et al. 2008; Zheng \& Sun 2011). The importance of appropriate selection of the reference gene(s) for quantitative gene expression analysis regarding the exposure of heavy metal to abalone was clearly verified with the validation experiment using the $M T$ gene conducted in this study. $M T$ protein is a non-enzymatic multiplayer playing essential roles in metal homeostasis and detoxification, and due to its high inducibility at both the mRNA and protein levels, $M T$ has been long recognized as a potential biomarker of heavy metal with aquatic organisms (Mao et al. 2012). In the present study, the amounts of heavy metal (Cd)-induced $M T$ expression were differentially calculated depending on selected reference genes having different 
expression stabilities. Our data potentially suggest that the transcriptional response of $M T$ could be either underestimated (as evidenced in the gill; see Fig. 4a) or overestimated (in the hepatopancreas; Fig. 4b) if "wrong" references were used, although the direction of transcriptional response (i.e., upregulation or downregulation) was not affected by the kinds of reference genes tested. Collectively, the overall findings from this study confirm not only that the reference genes chosen under a certain experimental treatment conditions may not be universally applicable to other conditions but also that expression stability of a given reference gene could not have consensus across tissue types.

\section{Conclusions}

Twelve potential candidate reference genes for RTqPCR-based expression studies were evaluated in the gill and hepatopancreas tissues of abalone $H$. discus hannai under heavy metal exposure conditions. Based on multiple statistical algorithms, both gill and hepatopancreas subsets recommended ribosomal protein genes (particularly $R P L 7$ ) as stable reference genes while traditionally known HKGs such as B-TU and/or GAPDH genes as inappropriate references. Our results also highlight the importance of selecting the suitable reference gene(s) for RT-qPCR studies, considering not only the experimental conditions but also tissue types under evaluation. Data from this study could be a good fundamental basis to guide future design of RT-qPCR studies with respect to metal regulation/detoxification and other related physiological aspects in this abalone species.

\section{Abbreviations}

ACTB, cytoskeletal $\beta$-actin; B-TU, $\beta$-tubulin; Cq, quantification cycle; $C t$, cycle threshold; EF1A, elongation factor-1 alpha; GAPDH, glyceraldehyde-3phosphate dehydrogenase; NGS, next-generation sequencing; PPIB, peptidylprolyl cis-trans isomerase $B ; R P L$, ribosomal protein $L$ isoform; $R T-q P C R$, quantitative reverse transcription-PCR; UBE2, ubiquitin-conjugating enzyme E2

\section{Acknowledgements}

The authors thank Mr. Min Soo Gwon and Ms. Eun Jeong Kim for their technical assistances on the management and tissue sampling of experimental abalone specimens.

\section{Funding}

This study was supported by the grant from the Golden Seed Project (GSP) Ministry of Oceans and Fisheries, Republic of Korea. The GSP has supported funds for the design of study, preparation of experimental abalones, expression analysis, and interpretation of data described in this paper.

\section{Availability of data and materials}

We do not think we have additional supporting data that will be shared. Every gene sequence used has already been deposited and is available in GenBank under the accession numbers provided in this paper. All other relevant data have already been used to present the tables and figures in this paper.

\section{Authors' contributions}

SYL carried out the biological stimulatory experiments using abalones and all the gene expression studies. YKN designed the study, performed bioinformatics analysis, and drafted the manuscript. All authors read and approved the final manuscript.

\section{Competing interests}

The authors declare that they have no competing interests.

\section{Consent for publication}

Not applicable.

\section{Ethics approval and consent to participate}

Not applicable.

Received: 27 February 2016 Accepted: 11 June 2016

Published online: 23 June 2016

\section{References}

Amiard JC, Amiard-Triquet C, Barka S, Pellerin J, Rainbow PS. Metallothioneins in aquatic invertebrates: their role in metal detoxification and their use as biomarkers. Aquat Toxicol. 2006;76:160-202.

Andersen $\mathrm{CL}$, Jensen JL, Ørntoft TF. Normalization of real-time quantitative reverse transcription-PCR data: a model-based variance estimation approach to identify genes suited for normalization, applied to bladder and colon cancer data sets. Cancer Res. 2004;64:5245-50.

Bustin SA, Benes V, Garson JA, Hellemans J, Huggett J, Kubista M, et al. The MIQE guidelines: minimum information for publication of quantitative real-time PCR experiments. Clin Chem. 2009;55:611-22.

Cho YS, Lee SY, Kim KH, Nam YK. Differential modulations of two glyceraldehyde 3-phosphate dehydrogenase mRNAs in response to bacterial and viral challenges in a marine teleost Oplegnathus fasciatus (Perciformes). Fish Shellfish Immunol. 2008;25:472-6.

Cho YS, Kim DS, Nam YK. Isoform-specific response of two GAPDH paralogs during bacterial challenge and metal exposure in mud loach (Misgurnus mizolepis; Cypriniformes) kidney and spleen. J Fish Pathol. 2011;24:269-78.

De Santis C, Smith-Keune C, Jerry DR. Normalizing RT-qPCR data: are we getting the right answers? An appraisal of normalization approaches and internal reference genes from a case study in the finfish Lates calcarifer. Mar Biotechnol. 2011;13:170-80.

Doak SH, Zair Z. Real-time reverse-transcription polymerase chain reaction: technical considerations for gene expression analysis. In: Parry JM, Parry EM, editors. Genetic toxicology: principles and methods, methods in molecular biology. New York: Springer; 2012. p. 251-70.

Du Y, Zhang L, Xu F, Huang B, Zhang G, Li L. Validation of housekeeping genes as internal controls for studying gene expression during Pacific oyster (Crassostrea gigas) development by quantitative real-time PCR. Fish Shellfish Immunol. 2013;34:939-45.

Fernandes JMO, Mommens M, Hagen O, Babiak I, Solberg C. Selection of suitable reference genes for real-time PCR studies of Atlantic halibut development. Comp Biochem Physiol B. 2008;150:23-32.

Guénin S, Mauriat M, Pelloux J, Van Wuytswinkel O, Bellini C, Gutierrez L. Normalization of qRT-PCR data: the necessity of adopting a systematic, experimental conditionsspecific, validation of references. J Exp Bot. 2009;60:487-93.

Hellemans J, Mortier G, De Paepe A, Speleman F, Vandesompele J. qBase relative quantification framework and software for management and automated analysis of real-time quantitative PCR data. Genome Biol. 2007;8:R19.

Hwang PP, Lee TH, Lin LY. lon regulation in fish gills: recent progress in the cellular and molecular mechanisms. Am J Physiol Regul Integr Comp Physiol. 2011;301:R28-47.

Kim KY, Lee SY, Cho YS, Bang IC, Kim KH, Kim DS, et al. Molecular characterization and mRNA expression during metal exposure and thermal stress of copper/ zinc- and manganese-superoxide dismutases in disk abalone, Haliotis discus. Fish Shellfish Immunol. 2007;23:1043-59.

Kim KY, Lee SY, Cho YS, Bang IC, Kim DS, Nam YK. Characterization and phylogeny of two $\beta$-cytoskeletal actins from Hemibarbus mylodon (Cyprinidae, Cypriniformes), a threatened fish species in Korea. DNA Seq. 2008;19:87-97.

Kubista M, Andrade JM, Bengtsson M, Forootan A, Jonák J, Lind K, et al. The realtime polymerase chain reaction. Mol Asp Med. 2006;27:95-125.

Le DT, Aldrich DL, Valliyodan B, Watanabe Y, Ha CV. Evaluation of candidate reference genes for normalization of quantitative RT-PCR in soybean tissues under various abiotic stress conditions. PLoS One. 2012;7:e46487. 
Lee SY, Kim DS, Nam YK. Genomic organization, tissue distribution and developmental expression of glyceraldehyde 3-phosphate dehydrogenase isoforms in mud loach Misgurnus mizolepis. Fish Aquat Sci. 2013;16:291-301.

Li R, Shen Y. An old method facing a new challenge: re-visiting housekeeping proteins as internal reference control for neuroscience research. Life Sci. 2013;92:747-51.

López-Landavery EA, Portillo-Lopez A, Gallardo-Escarate C, Rio-Portilla MAD. Selection of reference genes as internal controls for gene expression in tissues of red abalone Haliotis rufescens (Mollusca, Vetigastropoda; Swainson, 1822). Gene. 2014;549:258-65.

Mao $\mathrm{H}$, Wang DH, Yang WX. Involvement of metallothionein in the development of aquatic invertebrate. Aquatic Toxicol. 2012;110-111:208-13.

Øvergård AC, Nerland AH, Patel S. Evaluation of potential reference genes for real time RT-PCR studies in Atlantic halibut (Hippoglossus hippoglossus L.); during development, in tissues of healthy and NNV-injected fish, and in anterior kidney leucocytes. BMC Mol Biol. 2010;11:36.

Park CJ, Kim SY. Abalone aquaculture in Korea. J Shellfish Res. 2013;32:17-9.

Pfaffl MW, Tichopad A, Prgomet C, Neuvians TP. Determination of stable housekeeping genes, differentially regulated target genes and sample integrity: BestKeeper-Excel-based tool using pair-wise correlations. Biotechnol Lett. 2004;26:509-15.

Qiu R, Sun B, Fang S, Sun L, Liu X. Identification of normalization factors for quantitative real-time RT-PCR analysis of gene expression in Pacific abalone Haliotis discus hannai. Chin J Oceanol Limnol. 2013;31:421-30.

Radonić A, Thulke S, Mackay IM, Landt O, Siegert W, Nitsche A. Guideline to reference gene selection for quantitative real-time PCR. Biochem Biophys Res Commun. 2004;313:856-62.

Rainbow PS. Trace metal bioaccumulation: models, metabolic availability and toxicity. Environ Intl. 2007;33:576-82.

Schmittgen TD, Livak KJ. Analyzing real-time PCR data by the comparative CT method. Nat Protoc. 2008;3:1101-08.

Shen GM, Jiang HB, Wang XN, Wang JJ. Evaluation of endogenous references for gene expression profiling in different tissues of the oriental fruit fly Bactrocera dorsalis (Diptera: Tephritidae). BMC Mol Biol. 2010;11:76.

Silva-Aciares F, Zapata M, Tournois J, Moraga D, Riquelme C. Identification of genes expressed in juvenile Haliotis rufescens in response to different copper concentrations in the north of Chile under controlled conditions. Mar Pollut Bull. 2011;62:2671-80.

Silver N, Best S, Jiang J, Thein SL. Selection of housekeeping genes for gene expression studies in human reticulocytes using real-time PCR. BMC Mol Biol. 2006;7:33.

Song Y, Choi MS, Lee JY, Jang DJ. Regional background concentrations of heavy metals ( $\mathrm{Cr}, \mathrm{Co}, \mathrm{Ni}, \mathrm{Cu}, \mathrm{Zn}, \mathrm{Pb})$ in coastal sediments of the South Sea of Korea. Sci Total Environ. 2014;482-483:80-91.

Taylor DA, Thompson EL, Nair SV, Raftos DA. Differential effects of metal contamination on the transcript expression of immune- and stress-response genes in the Sydney rock oyster, Saccostrea glomerata. Environ Pollt. 2013;178:65-71.

Türkmen M, Türkmen A, Tepe Y, Ates A, Gökkus K. Determination of metal contaminations in sea foods from Marmara, Aegean and Mediterranean seas: twelve fish species. Food Chem. 2008;108:794-800.

Udvardi MK, Czechowski T, Scheible WR. Eleven golden rules of quantitative RTPCR. Plant Cell. 2008;20:1736-7.

Vandesompele J, De Preter K, Pattyn F, Poppe B, Van Roy N, De Paepe A, et al. Accurate normalization of real-time quantitative RT-PCR data by geometric averaging of multiple internal control genes. Genome Biol. 2002;3:1-11. research0034

Wan Q, Whang I, Choi CY, Lee JS, Lee J. Validation of housekeeping genes as internal controls for studying biomarkers of endocrine-disrupting chemicals in disk abalone by real-time PCR. Comp Biochem Physiol C. 2011;153:259-68.

Wang WX, Rainbow PS. Influence of metal exposure history on trace metal uptake and accumulation by marine invertebrates. Ecotoxicol Environ Saf. 2005;61:145-59.

Yuan M, Lu Y, Zhu X, Wan H, Shakeel M, Zhan S, et al. Selection and evaluation of potential reference genes for gene expression analysis in the brown planthopper, Nilaparvata lugens (Hemiptera: Delphacidae) using reversetranscription quantitative PCR. PLoS One. 2014;9:e86503.

Zhang Z, Hu J. Development and validation of endogenous reference genes for expression profiling of medaka (Oryzias latipes) exposed to endocrine disrupting chemicals by quantitative real-time RT-PCR. Toxicol Sci. 2007;95:356-68

Zheng WJ, Sun L. Evaluation of housekeeping genes as references for quantitative real time RT-PCR analysis of gene expression in Japanese flounder (Paralichthys olivaceus). Fish Shellfish Immunol. 2011;30:638-45.

Zhu L, Altmann SW. mRNA and 18S-RNA coapplication-reverse transcription for quantitative gene expression analysis. Anal Biochem. 2005;345:102-9.

\section{Submit your next manuscript to BioMed Central and we will help you at every step:}

- We accept pre-submission inquiries

- Our selector tool helps you to find the most relevant journal

- We provide round the clock customer support

- Convenient online submission

- Thorough peer review

- Inclusion in PubMed and all major indexing services

- Maximum visibility for your research

Submit your manuscript at www.biomedcentral.com/submit 